\title{
Implementation of Software Process Improvement through TSPi in Very Small Enterprises*
}

\author{
Edgar Caballero, Jose A. Calvo-Manzano, Gonzalo Cuevas, and Tomás San Feliu \\ Universidad Politécnica de Madrid, Facultad de Informática Campus de Montegancedo $S / \mathrm{N}$, \\ 28660 Madrid, Spain \\ ecaballerobolesfactory.com, \\ \{joseantonio.calvomanzano, gonzalo. cuevas, tomas. sanfeliu\} (apm. es
}

\begin{abstract}
This article shows an experience in a very small enterprise related to improving software quality in terms of test and process productivity. A customized process from the curtent organizational process based on TSPi was defined and the team was trained on it. The pilot project had schedule and budget constraints. The process began by gathering historical data from previous projects in order to get a meastirement repository. Then the project was launched and some metrics were collected. Finally, results were analyzed and the improvements verified.
\end{abstract}

Keywords: TSPi, Software Quality. Process Improvement, Very Small Enterprise.

\section{Introduction}

An inappropriate quality and project management in software organizations generates cost overruns, low quality and cancelled projects [1]. The main reason for this problem is the lack of resources to invest in defining and improving their processes [2]. Some process models like CMMI are not affordable for small organizations [2].

Organizations have recognized that the control of their software processes affects the success of their projects, "they know what to do but not how to apply it" [4]. A new research line based on process improvement in very small enterprises has arisen in order to facilitate competitive capabilities for this environment in a global market [10].

Garcia [9] and Serrano [2] show how to get CMMI maturity levels using TSP in small enterprises. Some CMMI level 5 organizations have improved their quality levels using TSP [4].

Team Software Process (TSP) is a framework that provides a process based on an excellent experience in planning and managing software projects [5]. It guides teams in managing schedule and quality [4].

This article shows a case study related to the implementation of software process improvement through the introduction to the Team Software Process (TSPi) in a very small enterprise. The case study has the following goals (see Table 1):

Authors listed alphabetically.

A. Riel et al. (Eds.): Euro\$PI 2010, CCIS 99. pp. 280-289, 2010.

(c) Springer-Veriag Berlin Heidelberg 2010 
Table 1. Case study goals

\begin{tabular}{ll}
\hline Number & Goal \\
\hline Goal 1 & Analyze project deviations. \\
Goal 2 & Determine effectiveness of the cuscomized process. \\
\hline
\end{tabular}

In order to achieve the case study goals, some measures were evaluated to compare the pilot project and the historical average data.

The organization had a project with schedule and budget constraints (non functional requirements). In order to accomplish with these requirements, the organization decided to use TSPi by assuming the risk of modifying its organizational process. Besides, there was not enough time and resources to elaborate a complete training in TSPi.

Therefore, the organization applied only the basic TSPi principles, defining a customized process as a result of combining TSPi and the organizational process (Activity 1 in Figure 1). Historical data were collected in order to facilitate the estimation of the pilot project (Activity 2 in Figure 1).

Then, the pilot project was launched (Activity 3 in Figure 1) and the strategy and planning phases were performed (Activity 4 in Figure 1). While the pilot project was developed, their measures were collected (Activity 5 in Figure 1). Finally, the achievement of the goals was verified (Activity 6 in Figure 1).

In the following sections, the article shows the context (the organization and the pilot project), the historical data collected, the customized process, the goals verification and, finally, the conclusions.

The schema showed in Figure 1 summarizes the process followed in the case study.

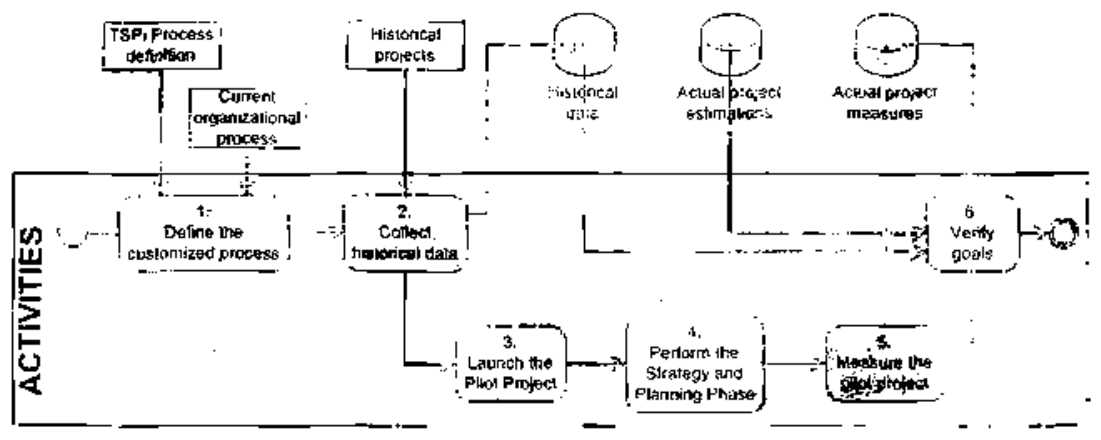

Fig. 1. Summary of case study

\section{Context: The Organization and the Pilot Project}

Bolesfactory is a Spanish very small enterprise of software development with an offshore center in Bolivia (www bolesfactory.com), which in the last year has increased 
drastically the number of their software projects. For this reason, their working scenario has changed to a new environment where many projects were developed simultaneously, and with a greater number of people involved.

As a result of an internal assessment, senior management detected that projects had begun to be delayed, dedicating additional efforts to accomplish their objectives. Moreover, products quality had decreased. Bolesfactory was interested in introducing a process model such as CMMI-DEV, but it could not afford for it.

Besides, the organization had a project (called PRO to preserve the confidentiality) with schedule and budget constraints. This project was selected as the pilot for the case study.

According to TSPi strategy phase, the project team established the project goals (see Table 2). As the project was delayed, the project team agreed to reduce the initial functionality by $20 \%$.

Table 2. Pilot project goals

\begin{tabular}{ll}
\hline Measure & Goal \\
\hline Schedule deviation & $<8.0 \%$ ( 1 week) (project constraint) \\
Effort deviation & $<15.0 \%$ (project constraint) \\
Size deviation & $<20.0 \%$ (historical average) \\
Test productivity & $<33.4$ hours/KLOC (historical average) \\
Project productivity & $>7.3 \mathrm{LOChour}$ (historical average) \\
$\%$ Release defects & $<5.0 \%$ \\
\hline
\end{tabular}

\section{Collecting the Historical Data}

Data on previous Bolesfactory projects were not enough. There were only schedule and budget data, but in order to verify the achievement of the pilot project goals, defects and effort by phase were needed. In addition, some derived metrics were calculated in order to analyze the project results.

In order to support the analysis, historical projects (His-1 to His-5) were divided into three phases (see Table 3):

Table 3. Project phases

\begin{tabular}{ll}
\hline Phase & Description \\
\hline Development & From project launch until unit tesis \\
Test & It includes integration and system tests \\
Operation & From the deployment until three months up \\
\hline
\end{tabular}

Effort and defect data of these phases are approximated values because there was no previous data repository. Table 4 summarizes the basic and derived measures applied in order to get the historical average that was used to compare the new customized process results. 
Table 8. Sub-goal 5.2 results

\begin{tabular}{lrrr}
\hline Goal & Historical & \multicolumn{1}{c}{ PRO } & \multicolumn{1}{c}{ Reduction } \\
\hline \% Schedule deviation & $21.4 \%$ & $7.7 \%$ & $64.0 \%$ \\
\% Effort deviation & $55.9 \%$ & $18.00 \%$ & $67.8 \%$ \\
\% Size deviation & $33.7 \%$ & $22.6 \%$ & $33.0 \%$ \\
\hline
\end{tabular}

Figure 2 shows graphically the improvement obtained by applying the new customized process. The deviation between the estimated and actual measures was reduced.

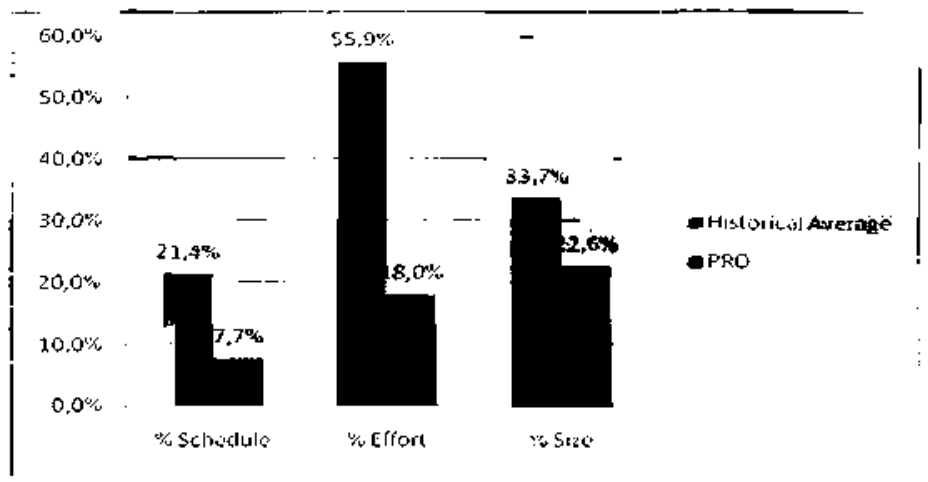

Fig. 2. Estimation deviations reduction

\section{Goal 2 - Determine Effectiveness of the Customized Process}

In order to verify the achievement of this goal, measures were evaluated comparing the PRO and the historical average data (see Table 4). The formula applied for the reduction is: \% Reduction $=[($ Historical - PRO $) /$ Historical $] * 100 \%$

\section{I Verify the Productivity Improvement}

The operation defect density ( $\rho$ ), the test productivity and the process productivity were analyzed in order to verify the productivity improvement. Note that the goal values were established using the average of the historical data (see Table 9).

Table 9. Goal 2 results

\begin{tabular}{lrrrr}
\hline Goal & Historical & PRO & & Reduction \\
\hline$\rho$ Operation defects [def./KLOC] & 2.0 & 1.2 & $40.0 \%$ \\
Test productivity [hour/KLOC] & 33.4 & 13.2 & $60.5 \%$ \\
Process productivity [LOC/Hour] & 7.3 & 7.6 & $-4.1 \%$ \\
\hline
\end{tabular}


The TSPi phases were used in the new process in order to get their procedures and metrics benefits, but the intermediate products, such as requirements or design specifications, were based on the previous organizational process in order to reduce the change impact.

The focus on quality is the main difference with the previous organizational process. Examples of this approach are the quality plan related to the phases and process performance, inspections and reviews.

The project team was empowered to estimate and plan the project balancing the workload. Also, a clearly role definition was adopted.

Table 5 shows the basic TSPi principles applied in the new customized process and the difference with the previous process.

In the next sections, the achievement of the case study goals will be verified

\section{Goal 1 - Analyze Project Deviations}

\subsection{Finish the Project within the Established Schedule, Effort and Size}

In order to verify the achievement of this sub-goal, measures were evaluated based on the initial plan (see Table 1). The formula applied to calculate the deviations is: \% Deviation $=[($ Estimation - Actual $) /$ Estimation $] * 100 \%$.

The results obtained in the project related to schedule, size and effort are (see Table 6):

Table 6. Estimation vs. Actual

\begin{tabular}{lrrr}
\hline Measure & Estimation & Actual & \% Deviation \\
\hline Schedule [WEEK] & 13.0 & 14.0 & $-7.7 \%$ \\
Effort [HRA] & 950.0 & 1121.0 & $-18.0 \%$ \\
Size [KLOC] & 6.9 & 8.5 & $-23.2 \%$ \\
\hline
\end{tabular}

Table 7 shows that there was only one week of delay in the schedule. The effort can be considered acceptable because the actual value is close to the estimated value. The formula applied to calculate the deviations is: \% Deviation $=[($ Goal - Actual $) /$ Goal $* 100 \%$.

Table 7 . Sub-goal $\$ .1$ results

\begin{tabular}{llrr}
\hline Measure & Goal & Actual & Deviation \\
\hline Schedule deviation & $<8.0 \%$ (l week) & $7.7 \%$ & $3.8 \%$ \\
Effort deviation & $<15.0 \%$ & $18.0 \%$ & $-20.0 \%$ \\
Size deviation & $<20.0 \%$ & $22.5 \%$ & $-12.5 \%$ \\
\hline
\end{tabular}

\subsection{Reduce the Estimation Deviation in Relation to Historical Data}

In order to analyze this sub-goal, measures were evaluated comparing the PRO and the historical average data. The formula applied to calculate the reduction is: \% Reduction $=[$ (Historical $-\mathrm{PRO}) /$ Historical $] * 100 \%$

The estimation deviations were reduced (see Table 8). 
Table 4. Historical measures

\begin{tabular}{|c|c|c|c|c|c|c|}
\hline Measure & Hiș-1 & His-2 & His-3 & His.4 & His.5 & Average \\
\hline Size $[\mathrm{KLOC}]$ & 104.4 & 33.5 & 22.6 & 7.2 & 10.5 & 35.6 \\
\hline Schedule [Week] & 45.0 & 48.0 & 41.0 & 21.0 & 15.0 & 34.0 \\
\hline Effort [Hour] & 11579.0 & 4448.0 & 3096.0 & 1156.0 & 1630.0 & 4382.0 \\
\hline \% Test effort & $30.0 \%$ & $28.3 \%$ & $2.0 \%$ & $17.0 \%$ & $5.0 \%$ & $24.5 \%$ \\
\hline Productivity [LOC/Hour] & 9.0 & 7.5 & 7.3 & 6.2 & 6.4 & 7.3 \\
\hline Released defects & 250.0 & 60,0 & 38,0 & 17,0 & 18.0 & 77,0 \\
\hline$\%$ released defects & $19,0 \%$ & $16,2 \%$ & $11,9 \%$ & $12,2 \%$ & $12,0 \%$ & $14,3 \%$ \\
\hline Development defect & & & & & & \\
\hline density $(\rho)$ & 4,3 & 3,0 & 5,8 & 7,2 & 5.7 & 5.2 \\
\hline Test defect density $(p)$ & 5.9 & 6,3 & 6,7 & 9,7 & 6,9 & $7, k$ \\
\hline Operation defect density $(\rho)$ & 2,4 & 1,8 & 1,7 & 2,4 & 1,7 & 2,0 \\
\hline \% defect removed before test & $34,1 \%$ & $27,0 \%$ & $40,9 \%$ & $37.4 \%$ & $40,0 \%$ & $35,9 \%$ \\
\hline $\begin{array}{l}\text { \% defect removed before } \\
\text { operation }\end{array}$ & $81,0 \%$ & $83,8 \%$ & $88,1 \%$ & $87,8 \%$ & $88.0 \%$ & $85.7 \%$ \\
\hline activities effort & & & & & & \\
\hline [Hour] & 926.3 & 278.0 & 371.5 & 173.4 & 163.0 & 382.4 \\
\hline Failure activities effort [Hour] & 3473.7 & 1256.6 & 681.1 & 196.5 & 407.5 & 1203.1 \\
\hline $\mathrm{COQ}$ or Quality effort & & & & & & \\
\hline (Appraisal + failure) [Hour] & 4400.0 & 1534.6 & 1052.6 & 369.9 & 570.5 & 1585.5 \\
\hline \% Appraisal effort (Cost) & $8.0 \%$ & $6.3 \%$ & $12.0 \%$ & $15.0 \%$ & $10.0 \%$ & $10.3 \%$ \\
\hline \% Failure effort (Cost) & $30.0 \%$ & $28.3 \%$ & $22.0 \%$ & $17.0 \%$ & $25.0 \%$ & $24.5 \%$ \\
\hline$\%$ COQ or Quality effort & $38.0 \%$ & $34.5 \%$ & $34.0 \%$ & $32.0 \%$ & $35.0 \%$ & $34.7 \%$ \\
\hline \% Development effort (all & & & & & & \\
\hline activities that ar & $62.0 \%$ & $65.5 \%$ & $66.0 \%$ & $68.0 \%$ & $65.0 \%$ & $65.3 \%$ \\
\hline
\end{tabular}

Table 5. TSPi principles applied in the new process

\begin{tabular}{|c|c|}
\hline ceess & \\
\hline $\begin{array}{l}\text { Process well defined. It makes easier the } \\
\text { planning and monitoring of the project }\end{array}$ & $\begin{array}{l}\text { Proc } \\
\text { well }\end{array}$ \\
\hline $\begin{array}{l}\text { Team motivated, participative and } \\
\text { collaborative }\end{array}$ & $\begin{array}{l}\text { Only the project leader elaborates the } \\
\text { project plan and the tasks assignment }\end{array}$ \\
\hline $\begin{array}{l}\text { Quality focus based on an early defect } \\
\text { detection and removing }\end{array}$ & $\begin{array}{l}\text { Since the schedules are constrained, the } \\
\text { quality was not considered }\end{array}$ \\
\hline ction of inspection activities in the & ws without a quality \\
\hline $\begin{array}{l}\text { plan in order to avoid schedule and } \\
\text { eviation }\end{array}$ & $\begin{array}{l}\text { th cost and schedule pre- } \\
\text { nstrained }\end{array}$ \\
\hline $\begin{array}{l}\text { ring and project visibility with the } \\
\text { value method }\end{array}$ & $\begin{array}{l}\text { no mechanism to monitor the } \\
\text { tus }\end{array}$ \\
\hline analyze the project and to & $\begin{array}{l}\text { meetings and they are } \\
\text { there are problems }\end{array}$ \\
\hline
\end{tabular}

\section{The Customized Process}

The customized process blends the basic TSPi principles and the previous organizational process. Once the new process was defined, the project started with training on the new process and the launching meeting. 
One of the best results of this project was the reduction of the released defects. This was possible because the quality TSPi principles were applied, introducing reviews and inspections to get an early defect detection.

Figure 3 shows a comparison between the historical and the pilot project productivity measurements. The dotted line represents the historical average values.
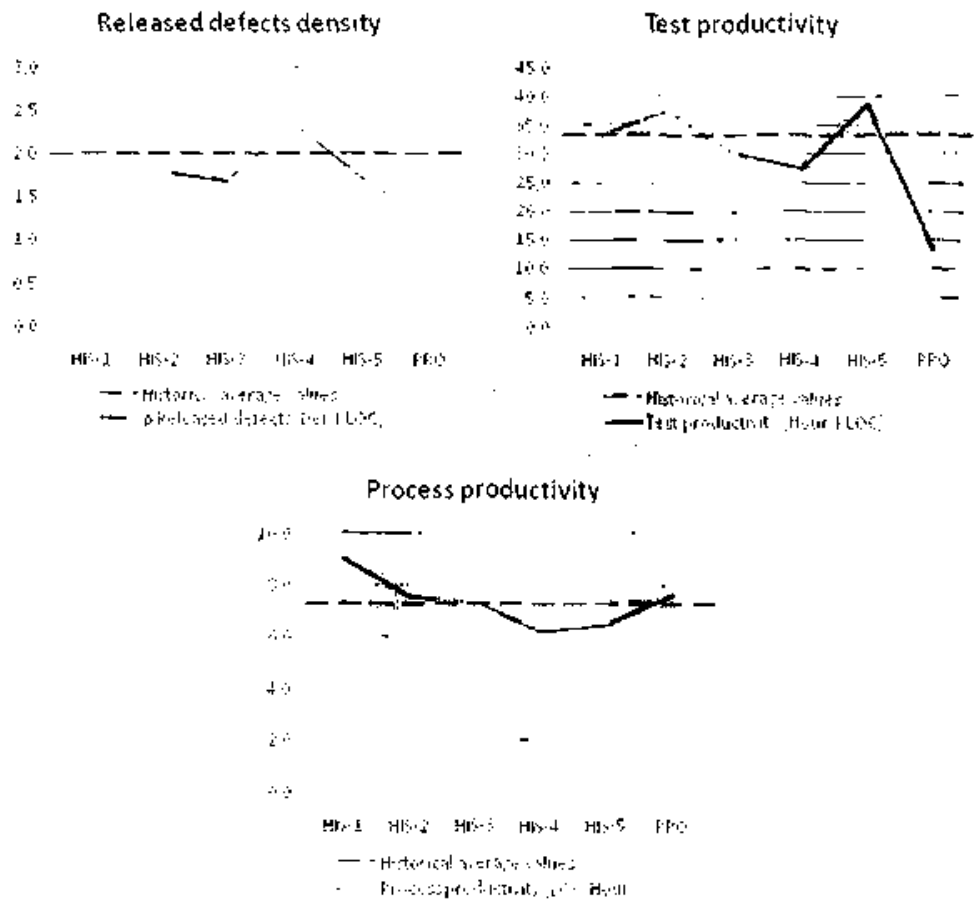

Fig. 3. Productivity Improvement

\subsection{Verify the Effectiveness and Quality of the New Customized Process}

TSPi uses the defect density to analyze the effectiveness of the process. The process is considered effective when every phase has less or equal defect density than the last one [6]. Figure 4 shows that the new customized process based on TSPi is more effective than the previous process because the defect density was reduced in every project phase.

In the previous process, most defects were found during the test phase, nevertheless in the new customized process this was reduced drastically because the early defect reduction was applied.

The Cost of Quality (COQ) is a measure that allows quantifying the size of the quality [7]. It has three components, but TSPi only works with two $(\mathrm{COQ}=$ Appraisal Costs + Failure Costs): 
- Appraisal Costs are the cost of evaluating the product to determine its quality level (reviews and inspections).

- Failure Costs are the cost of diagnosing a failure, making necessary fixes, and getting back into operation (compilation and test).

The improvement results about the cost of quality are showed in the Table I0.

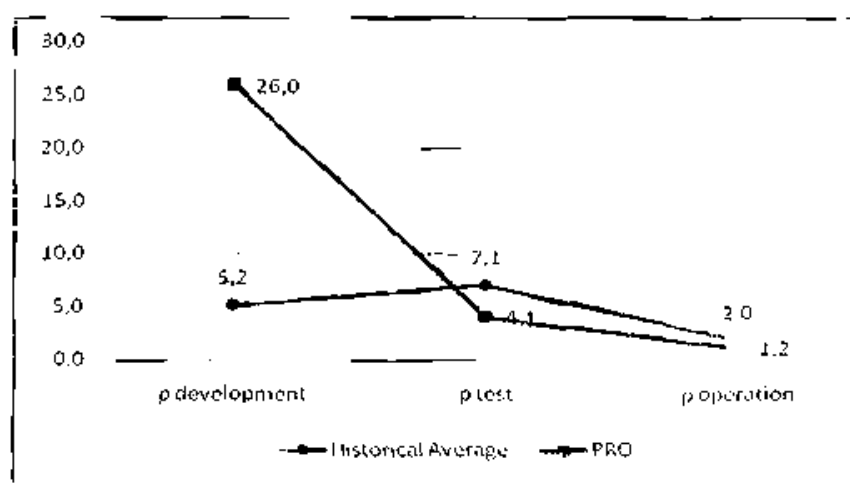

Fig. 4. Process improvement based in defect density

Table 10. Cost of quality components

\begin{tabular}{lrrr}
\hline Goal & Historical & \multicolumn{1}{c}{ PRO } & Reduction \\
\hline Appraisal activities effor [Hour] & 382.4 & 252.2 & $34.1 \%$ \\
Failure activities effort [Hour] & 1203.1 & 145.7 & $87.9 \%$ \\
COQ effort (Appraisal + failure) & 1585.5 & 398.0 & $74.9 \%$ \\
\% Appraisal effort & $10.3 \%$ & $22.5 \%$ & $-118.5 \%$ \\
\% Failure effort & $24.5 \%$ & $13.0 \%$ & $46.9 \%$ \\
\% COQ effort & $34.7 \%$ & $35.5 \%$ & $-2.31 \%$ \\
\% Development effort & $65.3 \%$ & $64.5 \%$ & $1.23 \%$ \\
\hline
\end{tabular}

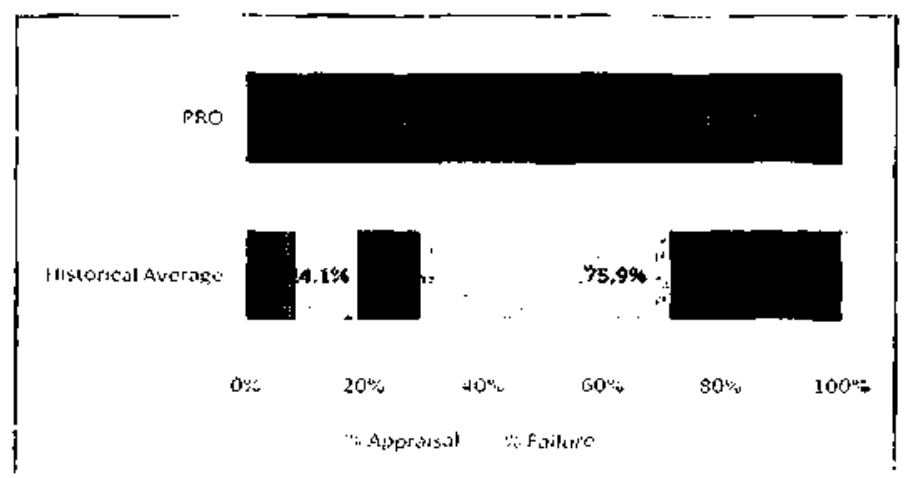

Fig. 5. Appraisal costs vs. Failure costs 
The COQ has not changed between the previous and the new customized process.

However, if the appraisal costs and failure costs are analyzed by themselves (separately), the improvement is clear. The new customized process uses inspections and formal reviews because it is based on an early defect reduction. These neu activities allowed increasing the appraisal costs and reducing the failure costs (see Figure 5).

\section{Conclusions}

The use of TSPi principles in the customized process allowed the achievement of project goals based on the following considerations.

1. The detailed plan, the change management and the weekly meetings were the main techniques introduced in the customized process.

2. The new customized process allows the team to be able to focus on the successful completion of the project itself.

3. During the project, the responsibility of the team members has been increased.

4. Test productivity has been increased and the re-work decreased by applying the early defect reduction principle.

5. The reviews, inspections and quality plans allowed a quality improvement. The team members understood the test phase as a quality evaluation and not as a defect detection activity.

6. The iterative strategy with TSPi cycles reduced the effort deviation thanks to the detailed project planning with shorter releases.

With an affordable investment in process definition, it has been demonstrated that TSPi is an effective altemative solution for process, quality and productivity improvement in a Very Small enterprise.

\section{References}

1. Standish group. CHAOS Report (2009)

2. Serrano, M., Montes, C., Cedillo, K.: An Experience on Implementing the CMMI in a Small Organization Using the TSP, pp. 81-92 (2006),

htep://wWw seí. cmu . edu/pub/documents/06.reports/ pdf /06sr001.pdf

3. International Process Research Consortium. JPSS White Paper. Improving Process in Small Settings (2006),

http: / / www . sed . cmu . edu/iprc/ipss-white-paper-v1-1.pdf

4. Noopur, D.: The Team Software Process in Practice: A Summary of Recent Results. SEI Technical Report CMU/SEI-2003-TR-0]4 (2003) 
5. Humphrey, W: Coaching Development Teams. Wesley Publishing Company, Reading (2006)

6. Humphrey, W.: Introduction to the Team Software Process. Addison-Wesley Publishing Company, Reading (1999)

7. Humphrey, W.: A Discipline for Software Engineering. Addison-Wesley Publishing Company, Reading (1995)

8. Garcia, S., Graettinger. C.. Kost, K.: Proceedings of the First International Research Workshop for Process Improvement in Small Settings. SEI Special Report CMU/SEI2006-SR-001 (2005)

9. Garcia, S.: Thoughts on Applying CMMI in Small Settings (2005), http: / /www . sei . cmu , edu/cmmi /adoption/pdf/garcia-thoughts , pdf

10. Glazer, H.: Time to Market vs. Process Discipline (2006),

http: / www sei . cmu . edu/iprc/sepg2006/glazer.pdf 